\title{
Jenízaros: la definición social de la élite militar del Imperio Otomano
}

(SS. XIV-XVII)

\section{The Janissaries. The Social Definition of the Military Elite of the Ottoman Empire $\left(14^{\text {th }}-17^{\text {th }}\right.$ Centuries $)$}

\author{
JAIME DENIS RODRÍGUEZ MADRAZO \\ Universidad Autónoma de Madrid \\ jaime.madrazo@gmail.com
}

Resumen: Los jenízaros fueron la base de la innovación militar para la expansión otomana, pero frente a lo que se suele decir no constituyen únicamente una elite bélica. El origen, la formación, las funciones y la relación sostenida con la sociedad turca son los ejes de este estudio, que concluye en que dicho cuerpo militar no se limitó a un mero carácter castrense. Además, prestaremos especial atención al cambio de lógica que se dio a lo largo del XVII en el seno del cuerpo.

Palabras clave: Jenízaros, Imperio Otomano, elite militar, bektasies, grupo social.

\begin{abstract}
The janissaries were the base of the military innovation for the Ottoman expansion; on the contrary, they do not merely constitute a warlike elite. Their origin, their creation, their functions and their relation with the Turkish society are the axes of this study, resulting in that the above mentioned military body did not limit itself to a merely military character. In addition, we will give special attention to the change in the Janissaries' logic of behaviour throughout the $17^{\text {th }}$ century.
\end{abstract}

Keywords: Janissaries, Ottoman empire, military elite, bektshies, social group.

Recibido: 24 de mayo de 2017; aceptado: 22 de noviembre de 2017; publicado: 27 de marzo de 2018. Revista Historia Autónoma, 12 (2018), pp. 61-77. e-ISSN: 2254-8726; DOI: https://doi.org/10.15366/rha2018.12.003. 
Introducción

Este estudio analiza el cuerpo de jenízaros, la elite del ejército otomano, y base de su expansión y del temor en Occidente. Nuestro objetivo es indagar en los orígenes históricos de la mayor potencia fronteriza con Europa entre los siglos XIV y XVII; un pueblo nómada cuyas aspiraciones se vieron sobredimensionadas en relación a los medios de que disponía y que, sin embargo, supo adaptarse creando el primer ejército profesional y permanente visto en el Viejo Continente desde los tiempos de Roma. La "guerra santa" contra el infiel pasó de ser un deber de todo musulmán a ser el del Estado Otomano, llevándola a cabo mediante la profesionalización bélica y, en especial, con la creación de la infantería jenízara.

Explicado el nacimiento de los jenízaros, se define el marco en que se produce, incidiendo en el proceso por el que estos soldados se convertirían en la elite otomana. Así, se analiza después el devsirme o sistema educativo que convertía a niños europeos y cristianos en la cabeza del ejército turco y que algunos autores han querido equiparar a la agogé espartana. Se explica el proceso de conversión de estos niños, no solo religiosa, sino aplicable a todos los ámbitos de su vida y del cual derivará nuestro cuerpo.

La guardia de jenízaros no tuvo únicamente funciones militares. A continuación nos ocupamos de sus tareas diarias, su estilo de vida y su relación con el resto de la sociedad turca. En lo que a su forma de vida se refiere, analizamos concretamente su filiación religiosa a la orden bektasí, hecho que consideramos clave para su definición social.

Por último, y para concluir, analizamos cómo la guardia jenízara dejó atrás la virtud que la caracterizó en sus primeros siglos de vida para, en el siglo XVII, desarrollar una transformación cuya consecuencia fue la mutación total del cuerpo. Por tanto, creemos necesario hacer una división interna en lo que a la comprensión de los jenízaros se refiere.

¿Qué consideración social tuvieron los jenízaros dentro del Imperio? ¿Qué elementos favorecieron estas consideraciones? Estas son algunas de las preguntas a las que pretendemos dar respuesta en este estudio.

\section{La necesidad de un ejército profesional}

El origen del Imperio Otomano reside en las tribus nómadas de la región de Anatolia. Estas procedían de la gran estepa euroasiática. La falta de estabilidad de la vida esteparia hace que el nomadismo estuviese "predestinado" para aquellos que en ella habitaban. Debido a la 
aparición de diferentes entidades políticas a lo largo de la Historia, el pueblo turco fue empujado a la región de Anatolia, siempre supeditado a cuerpos "estatales" de mayor envergadura. En este contexto apareció el Islam en la vida turca convirtiéndose, además, en la vía para el desarrollo de este pueblo. No en vano, esta religión justificará la guerra de incursión frente al infiel ${ }^{1}$. Podemos definir dicha legitimación religiosa a través de los gazi, un trampolín para la eclosión de la cultura turca y su expansión ${ }^{2}$.

Entender la autonomía política otomana obliga a remontarnos al Imperio Selyúcida de Anatolia, amedrentado ante la imposibilidad de actuación frente a las invasiones mongoles durante los siglos XIII-XIV ${ }^{3}$. En este contexto, debemos atender a la situación de los otomanos, que ocupaban una provincia fronteriza. En este clima surgió la figura de Osmán, considerado como el padre de la dinastía otomana. Este personaje no era sino el líder o caudillo de un ejército de nómadas turcomanos organizado todavía en tribus, cuya acción se incluye dentro del movimiento gazi. Las victorias cosechadas por Osmán le propiciarán el reconocimiento selyúcida como bey de su propio beyliq ${ }^{4}$, ubicado en Bitinia tras la superación de las fortificaciones bizantinas de Sakarya ${ }^{5}$. Este es el germen político inicial del posterior Imperio Otomano. Fruto de este proceso y, debido a su cercanía territorial con el "infiel”, Osmán se convirtió en una figura que atrajo a muchos guerreros provenientes de distintos ámbitos del islam ${ }^{6}$.

Con Orhán, hijo de Osmán, se produjo el asentamiento político de los otomanos que, sabiendo aprovechar las controversias de los principados colindantes, lograron erigirse como cabeza reconocida de los gazi. Esta posición no tendrá competencia a partir del colapso del principado de Aydin en 13467. Este hecho es crucial, pues en Anatolia dicho movimiento implicaba una movilización de masas ingentes ${ }^{8}$. Convertidos ya en la principal potencia de la zona, Orhán comienza a inmiscuirse en la sucesión al gobierno bizantino de igual manera que, previamente, habían hecho sus antecesores. Después, conquistó y estableció una base permanente en Gallípoli (1354), plaza en la orilla europea del Bósforo, desde la que continuaría su expansión. Los ejércitos originales de los turcos integraban fuerzas tanto musulmanas como

\footnotetext{
${ }^{1}$ Goodwin, Jason, Los señores del horizonte. Una historia del Imperio Otomano, Madrid, Alianza Editorial, 2004, pp. 24-33.

${ }_{2}^{2}$ Los guerreros de Dios. Todo aquel musulmán que lleva a cabo la guerra contra el infiel en nombre de Alá. La importancia de este término radica en el carácter de mártir que otorga al caído en combate contra el no musulmán. Supone pues, una concepción de la guerra y de la muerte que incentiva la acción bélica. Wittek, Paul, The rise of the Ottoman Empire, Nueva York, Royal Asiatic Society Books, 2012, pp. 111-116.

${ }^{3}$ El Imperio Selyúcida se extendió por los territorios de la Transoxania, Irán, Anatolia y Asia Menor. Fue el primer órgano político que recibió el poder temporal por parte del califa de Bagdag, creándose así el cargo de sultán. Este imperio será el entorno en el que se desarrollará el pueblo otomano hasta convertirse en su sucesor. Thoraval, Yves, Diccionario de civilización musulmana, Barcelona, Larousse, 1995, pp. 277-278. Sobre las invasiones mongoles véase Von Grunebaun, Gustave Edmund, El Islam II. Desde la caída de Constantinopla hasta nuestros días, Madrid, Siglo XXI, 1976, pp. 16.

${ }^{4}$ Bey corresponde al gobernador del beyliq, que es el nombre que reciben las divisiones territoriales del Imperio Selyúcida. Ibidem, p. 17.

${ }^{5}$ Imber, Colin, El Imperio Otomano. 1300-1650, Barcelona, Grupo Zeta, 2004, p. 26.

${ }^{6}$ Goodwin, Jason, Los señores del... op . cit., p. 29.

${ }^{7}$ Von Grunebaun, Gustave Edmund, El Islam II... op. cit., p. 19.

${ }^{8}$ Wittek, Paul, The rise of... op. cit., p. 115.
} 
cristianas, todas ellas en busca de la prosperidad personal que la guerra podía otorgar ${ }^{9}$. Pudiendo ser definido como un Estado naciente, cabe destacar su capacidad para aglutinar las ambiciones individuales de todos aquellos dispuestos a supeditarlas al nuevo estado otomano. Sin embargo, la importancia que llegaría a tener la lucha contra el infiel se demuestra en una inscripción de la mezquita de Bursa que reza: “Orhán, hijo de Osmán, gazi, sultán de los gazi, Señor del Horizonte, Amo del Mundo Entero"10, que refleja la importancia que suponía ser el máximo exponente de la guerra contra el "infiel". A pesar de este hecho, cabe recalcar la variedad de pueblos sobre los que recaía el gobierno otomano, abarcando tanto a musulmanes como a cristianos. Si unimos esto a la consideración de Bunes Ibarra sobre el estado de formación y definición en que se encuentra el estado otomano en los tiempos de Osmán y Orhán, nos hace considerar esta legitimación religiosa como la más factible y maleable en pos del desarrollo territorial ${ }^{11}$.

Al hablar de "guerra santa" vinculada a los gazi, debemos aclarar que esta no se hallaba institucionalizada. Se trataba de un derecho o incluso un deber de todo musulmán. Estamos ya en condiciones de explicar el sistema militar, pues fue la necesaria complejización de este el embrión de los jenízaros, objeto de nuestro estudio.

Un ejército formado por gazis era una fuerza tan valiosa como peligrosa, pues, como hemos mencionado antes, la hueste de Osmán estaba compuesta, en gran parte, por tribus nómadas que carecían de disciplina y cuya capacidad de actuación era muy limitada ${ }^{12}$. Esta radicaba en la composición de la tropa, que consistía en una caballería de arqueros cuya táctica de combate se basaba en la emboscada por sorpresa. Así, sería imposible de repeler por el enemigo gracias a la cuidadosa selección previa de un terreno abrupto y ventajoso para una rápida retirada ${ }^{13}$. Este método de combate, kleinkrieg, fue muy efectivo en la guerra a pequeña escala pero insuficiente para la de grandes conquistas, como refleja el fracaso de Osmán en su intento de conquistar Bursa, a la que los dirigentes otomanos pronto empezaron a aspirar ${ }^{14}$.

Durante el siglo XIV, estas tropas pasaron a ser un cuerpo auxiliar ${ }^{15}$. Como hemos estudiado, durante dicha centuria se produjo una "profesionalización" del ejército otomano. Con todo, la kleinkrieg no cayó en desuso, pues veremos su reminiscencia a través de los akinjis hasta el siglo XVIII. La profesionalización tiene como protagonista la creación de dos grandes cuerpos bélicos, la caballería timariota y la infantería jenízara ${ }^{16}$.

\footnotetext{
${ }_{9}^{9}$ De Bunes Ibarra, Miguel Ángel, El Imperio Otomano (1451-1807), Madrid, Síntesis, 2015, pp. 25-27.

${ }^{10}$ Goodwin, Jason, Los señores del... op. cit., p. 33.

${ }^{11}$ De Bunes Ibarra, Miguel Ángel, El Imperio Otomano... op. cit., p. 27.

${ }^{12}$ Wittek, Paul, The rise of the... op. cit., p. 114; Conrad, Philippe, "Los jenízaros", en Mourreau, Jean-Jacques (coord.), Los grandes cuerpos militares del pasado, Barcelona, Editorial ATE, 1980, pp. 85-163.

${ }^{13}$ Imber, Colin, El Imperio Otomano ... op . cit., p. 267.

${ }^{14} \mathrm{Se}$ puede definir como Kleinkrieg al tipo de acción bélica que consiste en cabalgadas de escaramuza rápida llevada a cabo por arqueros. Una vez realizado el ataque y perdido el factor sorpresa, la tropa se retira a terreno abrupto donde el ejército contrario no les puede seguir. Imber, Colin, El Imperio Otomano... op. cit., pp. 266-267; Von Grunebaun, Gustave Edmund, El Islam II... op. cit., p. 16.

${ }^{15}$ Imber, Colin, El Imperio Otomano... op. cit., p. 268.

${ }^{16}$ Los akinjis fueron jinetes originarios de la zona de Rumelia, cuyo papel consistía en ser la avanzadilla del ejército para allanar el terreno a través del miedo que sus acciones generaban. Fuera de temporada bélica su tarea
} 
2. Creación de los jenízaros

No conocemos el momento exacto de la creación del cuerpo de jenízaros, pero sí está claro que sucedió en el siglo xIv. De hecho, Imber, al igual que el historiador del siglo xv Uruc Bey, fijó la fecha de esta creación con Murat $\mathrm{I}^{17}$. Conrad en cambio, se la atribuye a Orhán ${ }^{18}$. Valga esta disonancia como reflejo de la complejidad a la hora de datar con exactitud la aparición de los jenízaros.

Durante el siglo XIV, el joven Estado otomano se hallaba en plena expansión, lo que implicaba encontrarse en el punto de mira de otros principados vecinos, tanto cristianos como musulmanes ${ }^{19}$. El carácter nómada de este pueblo tiene como consecuencia la falta de disciplina militar y la no aceptación de una jerarquía marcial. Así, tras un primer intento de "profesionalizar" el ejército otomano mediante la creación de los cuerpos de yayás y peyades, los dirigentes vieron la necesidad de dotar de tropa extranjera al ejército ${ }^{20}$. El lugar de procedencia elegido: la zona de los Balcanes, más concretamente Serbia, Grecia y Albania ${ }^{21}$.

Además de la disciplina, debía asegurarse la lealtad del nuevo ejército. Para ello, la solución sería el "rapto" de niños que, una vez apartados de sus padres y su tierra, serían preparados para la guerra. Este entrenamiento, que recibió el nombre de devsirme, no fue únicamente un adiestramiento militar sino una fuente de sirvientes para la Sublime Puerta.

\section{Funcionamiento del devsirme}

La naturaleza de este sistema radica en el tradicional "quinto", estipulado por la sharia y que consiste en el derecho del gobernante a que una quinta parte de los botines de guerra recayesen sobre él. Este derecho fue legislado por los otomanos y no se redujo a bienes materiales sino que incluyó también personas a través del llamado pençik ${ }^{22}$. La aceptación de

consistía en emprender misiones esporádicas en las que únicamente buscaban botín a la vez que causaban el temor en el enemigo. Véase Imber, Colin, El Imperio Otomano... op. cit., pp. 277-278. Este término también se aplica a cualquier jinete musulmán que acude a la guerra. Véase Conrad, Philippe, "Los jenízaros...” op. cit., p. 90.

${ }^{17}$ Imber, Colin, El Imperio Otomano ... op. cit., 269; Valdivia Valor, José, "Los Bektasíes y su influencia en la vida y cultura turcas", en Boletín de la Asociación Española de Orientalistas, 33 (1997), pp. 255-265.

${ }^{18}$ Conrad, Philippe, "Los jenízaros..." op. cit., p. 101.

${ }^{19}$ De Bunes Ibarra, Miguel Ángel, El Imperio Otomano... op. cit., p. 26.

${ }^{20}$ Cuerpos militares creados con anterioridad a los jenízaros y formados por otomanos. Al ser estos de tradición hípica y nómada, no acataron ningún tipo de disciplina, por lo que son la antesala que revela la necesidad de creación de los jenízaros. Véase Conrad, Philippe, "Los jenízaros...” op. cit., pp. 99-101.

${ }^{21}$ Yilmaz, Gulay, "Becoming a Devsirme. The training of Conscripted Children in the Ottoman Empire", en Campbell, Gwyn et al. (coords.), Children in Slavery Throught the Ages, Ohio, Ohio University Press, 2009 , pp. 119-134.

${ }^{22}$ Von Grunebaun, Gustave Edmund, El Islam II... op. cit., p. 31. 
esta ley no está totalmente clarificada por los investigadores. Hay quienes afirman que fue muy bien acogida en el seno turco, ya que permitiría extender la guerra santa y aumentaría el número de musulmanes en territorio conquistado ${ }^{23}$. Otros, sostienen que fue cuestionada debido a que los musulmanes consideraban al cristianismo y al judaísmo como "imperfectas realizaciones de la verdad" y se debe ejercer tolerancia con los monoteístas ${ }^{24}$. Los estudiosos de la ley islámica afirmaban que este hecho iba en contra de la ley divina que protegía a "la gente del libro", aquellos a los que se les han revelado las escrituras, los seguidores de Moisés y Jesucristo, que viven en territorio musulmán ${ }^{25}$. Sea como fuere, con o sin apoyo popular, el pençik se cobró nutriendo así al Estado otomano de la elite de infantería jenízara. No obstante, no debemos equiparar los prisioneros de guerra con los niños del devsirme, pues estos eran el resultado de una planificación preestablecida en aras de nutrir a la élite.

El proceso del devsirme comenzaba cuando el líder de los jenízaros, el agá, lo requería. Los niños que se elegían debían tener entre diez y dieciocho años, y la cantidad de seleccionados variaba según las necesidades del momento. El devsirme era un tributo obligatorio impuesto por el sultán a sus súbditos cristianos de la zona de los Balcanes, a pesar de no ser este el territorio exclusivo sobre el que podía recaer. Los lugares donde podía llevarse a cabo el reclutamiento también eran estipulados por el agá mediante un decreto. A estos emplazamientos eran enviados oficiales jenízaros que exigían un listado de los niños bautizados. Esta "cosecha", o "leva", ocasionó distintas posturas, pues no era extraño que dichos registros se intentasen falsificar para esconder a niños. Por el contrario, en Bosnia, por ejemplo, durante el sultanato de Mehmed II, la población cristiana solicitó participar en ella para evitar así el pago de impuestos económicos.

Los muchachos eran reunidos en el centro de los pueblos para comenzar la selección. Los oficiales preferían a los pertenecientes a las mejores familias, y aquellos con mejores condiciones físicas. Alcanzado el número requerido, se les organizaba en grupos de cien, ciento cincuenta o doscientos miembros para ser trasladados a la capital. Dicho viaje no se realizaba en malas condiciones, sino que se vigilaban los abusos y extravíos y se les vestía de rojo y con sombrero para facilitar el control ${ }^{26}$. Los muchachos eran importantes para el imperio, pues ellos acabarían engrosando tanto la élite del ejército, como los puestos de la administración de la Sublime Puerta.

Una vez llegaban a la capital, tras dos o tres días de descanso, eran llevados ante los líderes jenízaros para ser desnudados en busca de defectos corporales. Es en este momento cuando se cambiaba la identidad de los muchachos, pues se les convertía al Islam, se les circuncidaba y se les otorgaban nombres musulmanes. Tras esta inspección, se hacía una nueva selección de los más hermosos y talentosos, los cuales eran enviados a los palacios para destinar sus vidas a

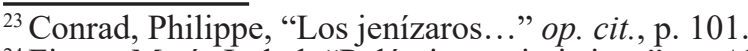

${ }^{24}$ Fierro, María Isabel, "Polémica anticristiana", en Abumalham, Montserrat (coord.), Textos fundamentales de la tradición religiosa musulmana, Madrid, Trotta, 2005, pp. 155-170.

${ }^{25}$ Imber, Colin, El Imperio Otomano... op. cit., p. 144; Yilmaz, Gulay, “Becoming a Devsirme...” op. cit., p. 120.

${ }^{26}$ Ibidem, pp. 120-122.
} 
La Puerta; los demás eran registrados como principiantes de infantería ${ }^{27}$. Esta primera división de los muchachos suponía una diferenciación en su formación. Asistimos así a la educación palaciega y a una militar de infantería. La primera, tenía lugar inicialmente en cuatro palacios: los de Iskender Celebi, Galatasaray, Edirne e Ibrahim Pasha. En este momento de su educación, los muchachos aprendían turco, árabe y persa, eran educados en la tradición del Corán, la ley islámica y su jurisprudencia y recibían entrenamiento militar. Cada cierto tiempo se hacía una nueva selección para decidir quiénes seguían con la educación y quiénes eran enviados a la infantería. La educación que recibían era muy estricta en aras de fortalecer la disciplina. Cada elemento de la vida cotidiana, como puede ser comer o pasear, tenía su momento y duración estrictamente definido. Los jóvenes eran enseñados a ser humildes y educados, así como a mostrar respeto a sus superiores mediante las leyes de protocolo (reverencias, besos de mano). Esta educación duraba, de promedio, catorce años y se realizaba en dos tipos de escuelas: las preparatorias y las ocupacionales. Como hemos dicho, no todos los niños que comenzaban el devsirme lo terminaban. Sin embargo, los que finalizaban, podían solicitar los puestos que deseasen dentro de la articulación institucional del Imperio, accediendo de este modo a los más altos cargos de la administración y del ejército ${ }^{28}$. Quizás uno de los mejores ejemplos de las posibilidades que abría el devsirme sea el visir Ibrahim Pachá quien, a pesar de su origen humilde llevó al Imperio Otomano a sus "años de oro" siendo Gran Visir de Solimán el Magnífico 29.

El entrenamiento militar se nutría de los descartados de la educación palaciega. El grupo de niños que no accedían a esta desde un principio, recibían un entrenamiento dividido en dos fases. El primero, consistía en enviarlos a una familia turca, en las zonas de Anatolia o Rumelia durante alrededor de cinco años. El objetivo de este viaje era que los niños crecieran en un ambiente turco-islámico, lejos de las costumbres de su tierra y de las tentaciones económicas que la ciudad podía ofrecer, así como adquirir una férrea disciplina mediante el duro trabajo que debían desempeñar ${ }^{30}$.

Tras esta primera fase, el segundo nivel se desarrollaba en los barracones de Estambul, Gallípoli y Adrianópolis (Edirne). A estos emplazamientos llegaban cuando los estudiantes — acemi oglans - ascendían al cuerpo de infantería. La educación tenía una parte religiosa, a cargo de los capellanes bektasies que analizaremos posteriormente. Igual que los destinados a los palacios, aquí los jóvenes aprendían literatura, preceptos del Corán, principios del gobierno, etc. Mientras continuaban con su preparación militar y seguían en los barracones, realizaban tareas de mantenimiento de la ciudad tales como limpieza o transporte de suministros, llegando incluso a sustituir a los jenízaros en sus tareas de control del orden y apagado de incendios, mientras ellos estaban en campaña. Llevaban cinturones de diferentes colores, blancos, azules, negros o amarillos para diferenciarlos según su edad. Esta fase de su preparación culminaba

\footnotetext{
${ }^{27}$ Imber, Colin, El Imperio Otomano ... op. cit., pp. 150-151.

${ }^{28}$ Yilmaz, Gulay, "Becoming a Devsirme..." op. cit., p. 123.

${ }^{29}$ De Bunes Ibarra, Miguel Angel, El Imperio Otomano... op. cit., pp. 87-88.

${ }^{30}$ Yilmaz, Gulay, "Becoming a Devsirme..." op. cit., p. 124.
} 
cuando el cuerpo de jenízaros requería de más hombres. Tras toda esta educación, lo que hoy denominaríamos como "graduación" respondía a un ritual totalmente definido. Este consistía en la reunión de aquellos que se "graduaban", en posición de formación ante los cuarteles. Una vez organizados, eran llamados por el oficial de uno en uno para recibir una bofetada y un tirón de orejas sin poder mostrar objeción alguna. El nuevo jenízaro mostraba, de esta manera, su total obediencia y disciplina. Tras esto, eran asignados a una compañía en la que debían besar la mano del oficial para que este les llamara Yoldach, camarada. Finalizado el ritual, los jóvenes quedaban constituidos como plenos jenízaros ${ }^{31}$.

\section{Resultado del devsirme: jenízaros, una diferenciación social}

Este cuerpo se encontraba dividido en ortas o unidades ${ }^{32}$. Para los tiempos de Solimán — primera mitad del siglo XVI—, nos encontramos con la agrupación de estas en tres subtipos: la guardia personal del sultán o sekban, los jenízaros al mando directo del agá y el resto de la hueste ${ }^{33}$.

La oficialidad de este ejército estaba formada por los denominados adjak agalari, los siete oficiales de mayor rango a la cabeza de los cuales se hallaba el agá, comandante en jefe de toda la hueste ${ }^{34}$. En un principio, la selección de este se llevaba a cabo por antigüedad, pero desde tiempos de Selim I (1512-1520), el cargo era designado por el sultán. Esta reafirmación del poder dinástico era ficticia, pues dicha decisión debía complacer a una tropa que podía llegar a deponerle como en el caso de Osmán II en 1622 o Ibrahim en $1648^{35}$.

A esta jerarquización del ejército se unían una serie de instituciones internas dedicadas a su organización, entre las que encontramos el diván del agá, que se reunía semanalmente; el jefe del estado mayor o kul kehaya/kehaya bey, que no podía ser destituido por el sultán a no ser que este se apoyara en los soldados de aquel; el regulador de prisiones o azar bachí; o el muzhir agá o jefe de la policía militar, cuya finalidad era controlar la relación del jenízaro con el Estado ${ }^{36}$.

En el aspecto judicial, los jenízaros también se hallaban al margen del resto de la sociedad, pues contaban con sus propios juzgados ${ }^{37}$. En el caso de que uno de ellos fuera condenado,

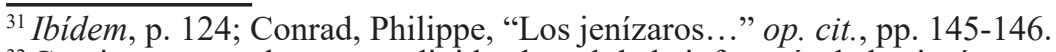

${ }^{32}$ Contingentes en los que se divide el total de la infantería de los jenízaros. Según el año en que nos encontremos pueden ser de cien a quinientos hombres. Conrad, Philippe, "Los jenízaros..." op. cit., p. 146.

${ }^{33}$ De Bunes Ibarra, Miguel Ángel, El Imperio Otomano... op. cit., p. 143.

${ }^{34}$ Conrad, Philippe, "Los jenízaros...” op. cit., p. 148.

${ }^{35}$ Ibídem, p. 148. También Goodwin, Jason, Los señores del... op. cit., pp. 422-423.

${ }^{36}$ Conrad, Philippe, "Los jenízaros..." op. cit., pp. 148-149.

${ }^{37}$ Goodwin, Jason, Los señores del... op. cit., p. 241.
} 
incluso por un delito civil o común, solo podía ser castigado por sus superiores ${ }^{38}$. Si la condena implicaba reclusión carcelaria, el soldado no compartía ni espacio con otros delincuentes ni el mismo tipo de ejecución, en el caso de ser esta la sentencia. De ser ajusticiado, el acto se hacía de noche en Rumili Hissar, de forma privada, siendo su cadáver arrojado al estrecho del Bósforo ${ }^{39}$.

Es posible distinguir dos tipos de calendario "laboral": el comprendido en campaña militar y el desarrollado fuera de esta temporada. En los periodos de paz, los jenízaros garantizaban la estabilidad del imperio mediante tareas como el apagado de incendios, la patrulla por las ciudades o funciones policiales que, durante las campañas bélicas, recaían en los adjemi oglans. De la misma forma, las fronteras conflictivas eran salvaguardadas de posibles amenazas exteriores por los contingentes jenízaros destinados en las guarniciones de estos territorios limítrofes, como la frontera húngara con las posesiones de los Habsburgo ${ }^{40}$.

En la vida propiamente bélica, como élite del ejército, ocuparon desde finales del XIV el lugar central de la línea de batalla, dotando al frente de una estabilidad impensable para otros ejércitos. Estabilidad y férrea disciplina eran la causa del terror ante los adversarios ${ }^{41}$.

Desde muy pronto, los jenízaros fueron los protagonistas de la expansión otomana, pues muchas victorias clave lo fueron por su intervención, o al menos así lo narra la tradición. De este modo, podemos encontrar, por ejemplo, la batalla de Nicea del primer tercio del siglo XIV, considerada como la primera gran victoria jenízara. Su resolución, junto con la posterior conquista de Nicomedia, posibilitó el control otomano de las costas del mar de Mármara. Otros triunfos fueron las batallas de Ankara (1402) o Varna (1444) en las que, debido a su disciplina y fidelidad al sultán, no huyeron de la batalla pese a encontrarse abandonados por el resto del ejército. Un último ejemplo es la batalla del Campo de los Mirlos o batalla de Kosovo (1398), ya que fue el enfrentamiento que mejor representó la relación entre jenízaros y la expansión turca, así como el primer gran choque entre los otomanos y la Cristiandad. La alianza de los reinos de Serbia, Bosnia y Bulgaria, amén de croatas y valacos, fue encabezada por el rey Lázaro de Serbia, muerto en el mismo conflicto tras el abandono de bosnios, húngaros y búlgaros. El protagonismo jenízaro radica en su valor durante el tremendo enfrentamiento entre las caballerías de ambos bandos. No retrocediendo, se mantuvieron firmes en su posición de combate, provocando así el choque de la caballería de Lázaro contra los jenízaros, quienes resolvieron la batalla a favor de los turcos ${ }^{42}$.

\footnotetext{
${ }^{38}$ González Castrillo, Ricardo, El viaje de Gabriel de Aristizábal a Constantinopla e 1784 según el manuscrito original II-1051 de la Biblioteca del Palacio Real de Madrid, Madrid, Fundación Universitaria Española, 1997, p. 54.

${ }^{39}$ Rumili Hissar, fortaleza jenízara situada en Estambul. Conrad, Philippe, “Los jenízaros...” op. cit., p. 152.

${ }^{40}$ Goodwin, Jason, Los señores del... op. cit., p. 240; Imber, Colin, El Imperio Otomano ... op. cit., p. 271.

${ }^{41}$ Conrad, Philippe, "Los jenízaros..." op. cit., p. 104; Imber, Colin, El Imperio Otomano ... op. cit., pp. 271-288.

${ }^{42}$ Conrad, Philippe, "Los jenízaros..." op. cit., p. 103-107; Von Grunebaun, Gustave Edmund, El Islam II... op. cit., p. 23; Imber, Colin, El Imperio Otomano... op. cit., p. 270.
} 
Para entender la total lealtad de los jenízaros hacia el sultán, es necesario explicar brevemente la naturaleza de su estatus social. Como hemos visto, en el devsirme, los niños reclutados no eran simples esclavos, sino que eran esclavos del sultán, kapikullari, "esclavos de la Sublime Puerta"43. Formaban una comunidad en la que no solo se incluían los jenízaros, sino todo aquel sirviente o dependiente directo del sultán ${ }^{44}$. Este estatus era vitalicio, y "tan solo la muerte podía liberar a los kapikullari de su deber de obediencia"45.

Esta dependencia directa del sultán se refleja en la simbología jenízara, especialmente a través de la marmita. En su vertiente simbólica, la marmita representa que, como kapikullari, son alimentados directamente por su señor. Los títulos de los oficiales también reflejan esta dependencia mediante referencias a la comida o el abastecimiento:

“[...] el vekil gardj (guardián de provisiones) correspondía a los tenientes actuales, el achtchibachí (cocinero en jefe), el muteveli (administrador de las cocinas), los karakuludjí (jefes de marmitones) y los sakkabachís (jefes de los acarreadores de agua), se refieren a nuestros tenientes, ayudante, sargentos y cabos"46.

El hecho de que estos símbolos tuvieran tanto peso muestra lo profundo de esta fidelidad. La propia marmita refleja esta cuestión. Podemos encontrar un ejemplo de esto al pensar en la rebelión contra el dominio otomano que se produjo en Egipto, que se declaró independiente en 1524 y que fue sofocada por la guarnición jenízara allí establecida ${ }^{47}$.

Cada orta contaba con sus propias marmitas; su defensa y protección era crucial, pues su pérdida significaba la deshonra de toda la orta, causando incluso la destitución de los oficiales y la imposibilidad de participar en los desfiles militares. Es inevitable recordar aquí a Roma y los aquilas imperiales de las legiones. Además de las marmitas, cada orta contaba con un símbolo específico que era representativo de todos sus miembros, quienes se lo tatuaban además de incorporarlo a sus marmitas. Toda esta simbología contribuye a la fuerte cohesión y solidaridad del grupo, que acaba generando desprecio hacia otros cuerpos militares e incluso a la población civil. Esta solidaridad se evidenciaba en los fondos a los que todos los jenízaros aportaban parte de su sueldo, y cuya finalidad era ayudar a las familias de los caídos o lisiados, así como el mantenimiento de los retirados y gestión de sus riquezas. Pese a todo, la estrecha relación sultán-jenízaros se vio progresivamente deteriorada en paralelo al desarrollo de los procesos de delegación del poder de los gobernantes turcos en visires, así como el fin de las conquistas. El origen de estos procesos llegó tras el reinado de Solimán el Magnífico, con el de Selim II. Esto,

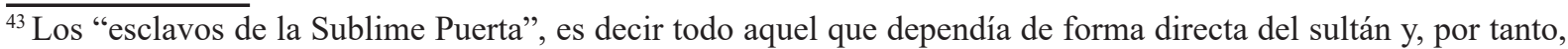
pertenecía a su familia. Von Grunebaun, Gustave Edmund, El Islam II... op. cit., p. 31.

${ }^{44}$ Goodwin, Jason, Los señores del... op. cit., p. 91.

${ }^{45}$ Ibídem, p. 292.

${ }^{46}$ Conrad, Philippe, "Los jenízaros...” op. cit., p. 148.

${ }^{47}$ De Bunes Ibarra, Miguel Ángel, El Imperio Otomano... op. cit., p. 88.
} 
unido a la intensa e imperturbable cohesión interna, fomentará la separación de los jenízaros respecto al resto de la sociedad, tesis en la que indagaremos en las conclusiones ${ }^{48}$.

\section{Vinculación religiosa a los Bektasí}

Para entender esta vinculación debemos remontarnos a los orígenes del Imperio Otomano. Como mencionamos en la introducción, el origen de este Estado reside en los pueblos nómadas del Asia Central que llegan a la actual Turquía poco después de aparecer el Islam. En los principios del siglo XIV, cuando se estaba asentando la religiosidad islámica en la población turca, adquirieron mucho peso una serie de órdenes religiosas ${ }^{49}$. De ellas destaca la de los seguidores de Hadji Bektash, cuya popularidad radicó en sus milagros avalados por su maestro Lokman Perende, discípulo del "santo turco más famoso del Asia Central" 50.

Desde su fundación, los jenízaros estuvieron ligados a la orden derviche de los bektasí

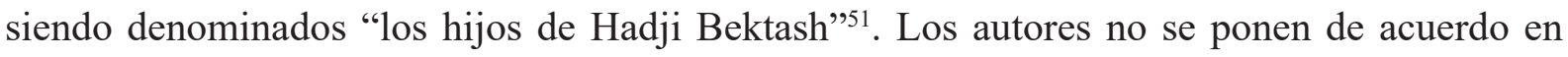
las causas de esta vinculación. Los hay que afirman que se debió a que este bendijo el nuevo ejército por petición de Orhán; otros sostienen que esta relación se debió a Alí Pasá, hermano de Orhán; y por último, están los que plantean que las prácticas de los bektasí, como el hecho de poder tomar vino o no imponer el velo a las mujeres, facilitarían las falsas conversiones al islam ${ }^{52}$.

Esta relación no se limita al aspecto militar, también podemos verla en lo religioso. La prueba que mejor lo manifiesta es la presencia de un derviche bektasí en cada orta, actuando a modo de capellán que arengaba a la tropa antes y durante la batalla. Desde la perspectiva de los religiosos propiamente dichos, el nombramiento de la cabeza de la orden, era oficializada simbólicamente por el $a g a^{53}$. Un último reflejo de esta cohesión es la ubicación de la marmita de Hadji Bektash en la mezquita exclusiva de los jenízaros ${ }^{54}$.

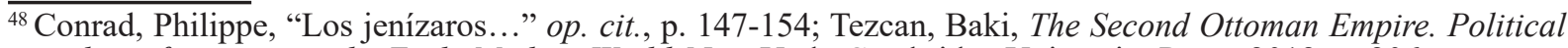
social tranformation in the Early Modern World, New York, Cambridge University Press, 2012, p. 206.

${ }^{49}$ Conrad, Philippe, "Los jenízaros..." op. cit., p. 101.

${ }^{50}$ Valdivia Valor, José, "Los Bektasíes y su influencia..." op. cit., p. 258.

${ }^{51}$ Ibidem, p. 262. Derviche: Musulmán sufí errante, que no sigue la doctrina ortodoxa, sino que sigue las enseñanzas de un maestro espiritual. Thoraval, Yves, Diccionario de civilización... op. cit., p. 109.

${ }^{52}$ Conrad. Philippe, "Los jenízaros...” op. cit., p. 101; Valdivia Valor, José, "Los Bektasíes y su influencia..." op. cit., p. 262; Goodwin, Jason, Los señores del... op. cit., p. 92.

${ }^{53}$ Conrad, Philippe, "Los jenízaros..." op. cit., p. 102; Valdivia Valor, José, "Los Bektasíes y su influencia..." op. cit., p. 262.

${ }^{54}$ Conrad, Conrad, "Los jenízaros...” op. cit., p. 147.
} 
Tal vez, el ejemplo más importante para entender esta relación sea el hecho de que en el siglo XIX la disolución del cuerpo de jenízaros correspondió a la antesala de la abolición de la orden derviche de los bekstasíes ${ }^{55}$.

\section{La desvirtuación de los jenízaros como cuna del conflicto social}

La definición virtuosa de la élite otomana que hasta aquí venimos dando se verá alterada a lo largo del siglo XVII. A lo largo del Seiscientos, vemos cómo las transformaciones de las rutas comerciales y los centros financieros, producidas por el surgimiento de nuevas potencias económicas, así como el fin de la guerra expansiva - sustento económico del Imperioprovocaron el inicio de la decadencia otomana. Entendiendo el sultanato de Solimán el Magnífico (1520-1566) como el periodo de máximo esplendor de La Puerta, analizaremos a continuación cómo la crisis del Imperio incentivó la acción sociopolítica de los jenízaros. Los procesos de delegación del poder por parte del sultán que se iniciaron tras sus años de gobierno, tuvieron como consecuencia la progresiva debilidad de la figura del descendiente de Osmán, lo que convirtió a los jenízaros, de manera inversamente proporcional, en un poder político de hecho con mayor influencia de la detentada anteriormente ${ }^{56}$.

A lo largo del XVII asistimos a un cambio en la lógica y el rol del cuerpo de jenízaros. De forma paralela, nos encontramos con el desarrollo técnico de la guerra, que ocasionó el crecimiento exponencial de las muertes en batalla, y la crisis generalizada del Imperio. Como consecuencia del cada vez mayor coste de efectivos, el devsirme perdió de forma progresiva su papel esencial como "cuna" de los jenízaros. A pesar de que este proceso se inició a finales del XVI, durante el sultanato de Selim II (1566-1574), fue a partir del XVII, cuando se aceptó la entrada masiva de musulmanes en el cuerpo, llegando a producirse una progresiva patrimonialización del puesto y siendo mercaderes, con unos intereses económicos muy marcados, los protagonistas del proceso ${ }^{57}$. Este enorme desarrollo de la guardia ${ }^{58}$, ocasionó la transformación del cuerpo que, así, pasó de conformar la élite y guardia real del Imperio a ser uno de los mayores cuerpos del ejército. De esta manera se acabó con la práctica mantenida hasta mediados del siglo XVI sobre el control del número de jenízaros, cuya naturaleza radicaba en el poder que el acantonamiento en Estambul les otorgaba. No obstante, cabe señalar que dicha apertura contó con cierta

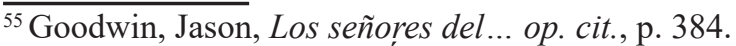

${ }^{56}$ De Bunes Ibarra, Miguel Ángel, El Imperio Otomano... op. cit., p. 163. Conrad, Philippe, "Los jenízaros...”op. cit., p. 154.

${ }^{57}$ De Bunes Ibarra, Miguel Ángel, El Imperio Otomano... op. cit., p. 135; Imber, Colin, El Imperio Otomano ... op. cit., p. 153; Tezcan, Baki, The Second Ottoman Empire... op. cit., pp. 207-210.

${ }^{58}$ Pasó de integrar 6000 efectivos a principios del XVI hasta 100000 con Murat IV (1623-1640). Véase Tezcan, Baki, The Second Ottoman Empire... op. cit., pp. 143-189.
} 
oposición, aunque infructuosa, de representantes de los jenízaros originarios del devsirme y cuyo argumento central sería evitar la desvirtuación del cuerpo. La consecuencia directa de esto fue el nacimiento del cuerpo de jenízaros como un poder de facto, al que considerar en las transiciones al trono ${ }^{59}$.

Ya desde el siglo Xv los jenízaros empezaron a explotar la dependencia de la dinastía hacia ellos ${ }^{60}$, en el siglo XVII confluyeron toda una serie de factores que les condujeron al protagonismo político. A finales del siglo XVI, a partir de Solimán el carácter militar del sultán como cabeza del ejército imperial desapareció. Debido a esto, la estrecha relación, casi paternalista, entre sultán y jenízaros de los siglos anteriores no hizo, en nuestra opinión, sino quebrarse $^{61}$. Como hemos visto en apartados anteriores, la relación sultán-jenízaros fue muy cercana a lo largo de los siglos XV y XVI. No obstante, asistimos en el XVII a una serie de cambios que alteraron dicho vínculo. La ausencia del sultán en el campo de batalla unida al nuevo sustrato social de la "guardia", tuvieron como consecuencia la ruptura de la estrecha relación. Mientras que los jenízaros estuvieron ligados al devsirme y compusieron la guardia personal y de élite del sultán, formal y socialmente respondieron a un estatus de esclavitud directa respecto a este. Sin embargo, esta dependencia cambió, si bien no en teoría sí en la práctica, en el momento en que la cifra de jenízaros aumentó exponencialmente ocasionando la transformación de esclavos a hombres libres ${ }^{62}$. La permanencia oficial del estatus privilegiado del jenízaro mantuvo su dependencia salarial directa del "estado" lo que, a su vez, sostuvo su sensibilidad a las fluctuaciones económicas del Imperio ${ }^{63}$. Como ya hemos mencionado, la incorporación de mercaderes al cuerpo de jenízaros fue mayoritaria, principalmente debido a las exenciones y beneficios, como la independencia jurídica respecto al resto de la sociedad, que el estatus de jenízaro otorgaba. Ahora bien, si los intereses económicos de los jenízaros no fueron totalmente homogéneos, en razón a la variedad de grupos que empezaron a formarlos, la conservación de su poder político sí fue de interés universal para todos ellos, provocando de esta manera la actuación del cuerpo ante la posible alteración de este ${ }^{64}$.

De esta manera, nos encontramos a lo largo de todo el siglo XVII la intervención jenízara en las dinámicas políticas en razón de la defensa de sus intereses socio-económicos en tanto que grupo social definido. De estas intervenciones, quizás las más reseñables fueron los magnicidios cometidos sobre sultanes; sin embargo, las mediaciones de menor envergadura fueron más habituales.

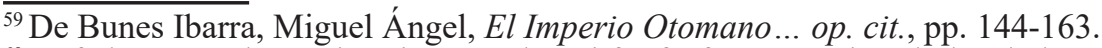

${ }^{60}$ Kafadar, Cemal, "Janissaries an other riffraff of ottoman istanbul: rebels without a cause?", en International Journal of Turkish Studies, 13 (2007), pp. 113-134.

${ }^{61}$ Imber, Colin, El Imperio Otomano... op. cit., p. 132; de Bunes Ibarra, Miguel Ángel, El Imperio Otomano... op. cit., p. 134.

${ }^{62}$ De Bunes Ibarra, Miguel Ángel, El Imperio Otomano... op. cit., p. 155.

${ }^{63}$ Ibidem, p. 188; Kafadar, Cemal, "Janissaries an other riffraff..." op. cit., pp. 113-134.

${ }^{64}$ Tezcan, Baki, The Second Ottoman Empire... op. cit., pp. 207-211.
} 
En 1622 se produjo el desenlace de todo un proceso por el que el sultán Osmán II se granjeó la enemistad de los jenízaros. Este, a consecuencia de la nueva situación del cuerpo de la que venimos hablando, comenzó una serie de reformas que se basaron en la reducción de los privilegios de la antigua guardia. Al mismo tiempo, Osmán caía en los "malos usos" respecto a los castigos impuestos ${ }^{65}$. Por último y como colofón, el historiador jenízaro Tugi narró que el sultán quiso sustituirles por un nuevo cuerpo de arcabuceros procedentes de Anatolia. El desenlace de todos estos hechos contra el estatus del cuerpo supuso la ejecución del sultán y la imposición de su sucesor, el sultán Mustafá ${ }^{66}$. En 1648, nos encontramos con una situación similar. Los excesivos gastos del sultán Ibrahim I, unidos a la corrupción generalizada en el gobierno, llevaron a La Puerta al borde de la quiebra, con un déficit en las arcas de ciento cincuenta millones de ásperos ${ }^{67}$. Como hemos mencionado anteriormente, los jenízaros, al depender económicamente del sultán, tuvieron una mayor sensibilidad ante las crisis. En este caso, la mala situación económica provocó la incapacidad para pagar las soldadas correspondientes, así como la disminución de la preparación de los soldados, provocando la reacción de la guardia a través de movimientos sediciosos reclamando sus sueldos y negándose a acudir a la guerra ${ }^{68}$. El desenlace de toda esta concatenación consistió en una conspiración nacida en el seno de los jenízaros que, aliándose con el gran muftí Abdurrahim y los ulemas, ejecutaron al visir de Ibrahim y depusieron a este en favor de su hijo Mehmet IV. Posteriormente, debido a la intención de cortesanos del Topkapi de restituir al depuesto sultán, se procedió a la ejecución de este en su celda ${ }^{69}$.

Es interesante ver cómo esta participación directa de los jenízaros en la política otomana se ve atenuada durante gobiernos en los que la autoridad del sultán era fuerte. El mejor ejemplo de ello lo encontramos en el gobierno de los Köprülü (1656-1683). Una de las características de esta etapa consistió en la represión, mediante ejecución, de los jenízaros instigadores de las revueltas. Del mismo modo, centraron sus esfuerzos en mantener el equilibrio económico del Imperio para, así, asegurar las soldadas y la estructura militar. La reacción ante las acciones de los jenízaros no se limitó a la familia de los Köprülü, como bien reflejaron Abaza Mehmet Pachá (beylerbey de Erzurum, Anatolia) o Tabaniyasi Mehmet Pacha (visir de Murat IV) quienes se dedicaron a la persecución y represión de las fuerzas agitadoras como fueron jenízaros, ulemas, etc. ${ }^{70}$. Además de la represión física, se generalizó a principios del XVII la necesidad de volver al pasado para solventar la situación decadente de La Puerta. Prueba manifiesta de ello fue la aparición de Las leyes de los jenizaros, una obra que recogía todas las prácticas que se habían

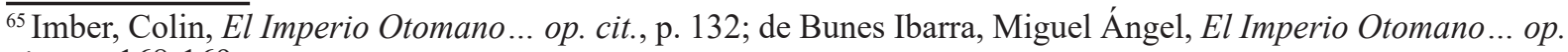
cit., pp. 168-169.

${ }^{66}$ De Bunes Ibarra, Miguel Ángel, El Imperio Otomano... op. cit., pp. 124-132.

${ }^{67}$ Ibídem, p. 126; de Bunes Ibarra, Miguel Ángel, El Imperio Otomano ... op. cit., p. 174.

${ }^{68}$ De Bunes Ibarra, Miguel Ángel, El Imperio Otomano... op. cit., p. 174.

${ }^{69}$ Imber, Colin, El Imperio Otomano ... op. cit., pp. 126-127.

${ }^{70}$ De Bunes Ibarra, Miguel Ángel, El Imperio Otomano... op . cit., pp. 170-189.
} 
abandonado en el seno de nuestra guardia, hecho al que el autor culpó de la pérdida de la virtud de los jenízaros ${ }^{71}$.

Pese a lo incisivo de nuestro discurso sobre la participación política de los jenízaros en el siglo XVII, no debemos caer en el equívoco de considerar que esta fue exclusiva de dicha centuria. Por ejemplo, Selim I (1512-1520) accedió al sultanato gracias al apoyo de los jenízaros frente a su padre ${ }^{72}$. Es importante en este punto entender cómo se habían desarrollado los juegos de poder en el Imperio antes del XVII y cómo se transformaron a lo largo de este. Hasta 1595, la herencia del sultanato podía recaer sobre cualquiera de los hijos del sultán gobernante que, además, eran nombrados, anteriormente, gobernadores en provincias del Imperio. De esta forma, las facciones de poder se conformaban en torno a estas figuras aspirantes al trono y aglutinadoras de intereses. Sin embargo, desde 1595 la lógica hereditaria cambió imponiéndose el principio de antigüedad a la hora de heredar, pues los hijos del sultán dejaron la gobernación de las provincias; o dicho de otra manera, y parafraseando a Baki Tezcan, la organización de poder otomana pasa en este momento de una concepción de una estructura piramidal con el sultán en la cúspide, a imaginarse como una tela de araña con él en medio ${ }^{73}$. De esta manera es como se entiende que el XVII suponga el desarrollo de las intrigas palaciegas en el Topkapi, y la formación de las facciones de poder dentro de este. Al igual que con los jenízaros, la concepción de la pérdida de los valores pretéritos como causa de la decadencia de la Puerta, se extendió al sultanato. Es por esto que Osmán II y Murat IV, intentaron recuperar el carácter guerrero que hasta Solimán el Magnífico había sido inherente a su cargo ${ }^{74}$.

Como consecuencia de esto, podemos atender a la "inmovilidad" de los jenízaros que, en tanto que grupo social definido, cohesionado y cerrado sobre sí mismo ante posibles transformaciones, defendió de forma recurrente sus intereses reaccionando ante la alienación de estos. En este apartado es interesante observar la excepcional sensibilidad que tuvieron en relación a la situación económica. De forma generalizada, vemos a lo largo de la historia tanto en forma cronológica como geográfica, la reacción de las distintas sociedades ante los periodos de crisis. Sin embargo, lo reseñable de los jenízaros es su independencia de actuación velando únicamente por el mismo grupo.

Ya hemos mencionado a lo largo del ensayo la mala relación que tuvieron frente a otros cuerpos del ejército e, incluso, frente al resto de la sociedad. Uno de los mejores ejemplos de ello sea tal vez la revuelta acaecida en Estambul tras el fracaso del segundo sitio de Viena en 1683. Tras el gobierno de los Köprülü la crisis del Imperio, tanto financiera como económica,

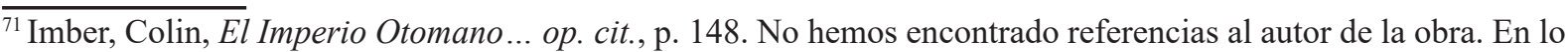
que se refiere a los jenízaros en concreto, podemos observar esta tendencia de "vuelta al pasado" a lo largo de toda la política reformista otomana, hasta el denominado "Periodo de los tulipanes". Este será el momento en el que la referencia de Solimán el Magnífico como paradigma de la grandeza otomana fue sustituida por una progresiva "occidentalización". Véase Kafadar, Cemal, "Janissaries an other riffraff..." op. cit., p. 114.

${ }^{72}$ Imber, Colin, El Imperio Otomano... op. cit., p. 116.

${ }^{73}$ Tezcan, Baki, The Second Ottoman Empire... op. cit., p. 193.

${ }^{74}$ Imber, Colin, El Imperio Otomano ... op. cit., pp. 126-132.
} 
se incrementó, hecho que provocó la deposición del sultán Mehmet IV en favor de Solimán II. Sin embargo, a pesar de esta sustitución de la cabeza de gobierno, los jenízaros asaltaron el Topkapi, depusieron al gran visir e iniciaron la revuelta en Estambul, de la cual, la mayor damnificada fue la población civil. De esta manera, se produjo un verdadero enfrentamiento entre los estambuliotas y los jenízaros ${ }^{75}$. Aunque este hecho pueda parecer anecdótico, refleja la total autonomía de acción del cuerpo, defensor únicamente de sus propios intereses.

\section{Conclusión}

El cuerpo militar de los jenízaros no puede ser considerado en exclusiva como un componente más del ejército otomano. Fueron la élite y estuvieron un escalón por encima del resto. Además del carácter castrense, fueron un grupo social definido. Esta diferenciación comenzaba en la condición vitalicia de los jenízaros. Además, nuestro cuerpo contaba con una organización prácticamente autónoma, pues su gobierno no dependía más que de los propios jenízaros y contaban con una justicia propia, ya que nadie sino ellos mismos les podía juzgar independientemente del delito e incluso en las cárceles se hallaban separados.

En lo religioso, estuvieron en estrecha relación con la orden de Hadji Bektash, mientras que el resto de la sociedad no. Esta diferenciación supone una de las más importantes para la definición social, pues siendo el Islam una religión que interfería considerablemente en la vida diaria de sus creyentes, la devoción de los jenízaros hacia los bektasíes les permitió quedar al margen de buen número de las restricciones religiosas. A la vez, hemos visto cómo se "autogestionaban" en lo relativo al mantenimiento de sus camaradas, pues existían sistemas internos para asegurar el buen estado de sus miembros y sus familias, así como la gestión de sus riquezas. Estas instituciones evolucionarían hasta ser reconocidas en el siglo XVIII como entidades corporativas que algunos autores han equiparado a organismos de carácter gremial ${ }^{76}$. A esto debemos unir el origen de estos hombres que, como hemos visto hasta finales del XVI no eran turcos, sino procedentes de la Europa cristiana.

Unido a todas estas diferencias teóricas, cabría apuntar la mala relación que, según Conrad, Imber o Goodwin, tenían con otros cuerpos del ejército y con el resto de la sociedad del imperio, manifestada en un cierto desprecio hacia estos. Dicha tensión se vería progresivamente agudizada durante el XVII-XVIII en relación a los intereses económicos de los nuevos integrantes de la "guardia".

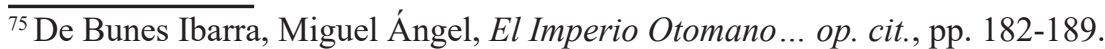

${ }^{76}$ Tezcan, Baki, The Second Ottoman Empire... op. cit., p. 207; Kafadar, Cemal, "Janissaries an other riffraff..." op. cit., p. 118.
} 
Toda esta teorización en torno a la lógica del cuerpo tuvo su manifestación material en sus acciones políticas. Como hemos visto, a lo largo del XVII, nuestro grupo social pasó de ser una "subsociedad" al margen de la gran sociedad turca, para, sin llegar a integrarse — pues defendieron su estatus social-, participar en los juegos políticos que regían el Imperio. Es más, creemos que el siglo XVII no debe ser considerado únicamente como el momento de desarrollo y mutación de la guardia jenízara, sino que supone una ruptura con la lógica anterior. Entendemos, por lo tanto, que no se debe pensar en el cuerpo de jenízaros como algo inmutable a lo largo de su historia, sino que el XVII supone un punto de inflexión en el que aparece una nueva realidad jenízara, provocando, de esta manera que, al igual que Tezcan habla de un "Primer Imperio Otomano" y un "Segundo Imperio Otomano" "77, podamos hablar de unos primeros jenízaros y unos segundos jenizaros.

La falta de interacción con la mayoría social del Gigante Turco fue un factor clave en lo que a la definición social del grupo se refiere. En nuestra opinión, la realidad sociológica de los jenízaros debería ser un tema de mayor calado bibliográfico debido a su desarrollo histórico. Habiendo nacido de forma paralela al Imperio Otomano, y siendo uno de los protagonistas de su expansión, entendemos que la ruptura sultán-jenízaros se produjo debido a una divergencia en el desarrollo de ambos. De esta forma, se entiende el desequilibrio entre la realidad teórica y la realidad práctica que desembocó en un estamento militar cuya base social se distanció de su naturaleza primitiva.

Por último, pensamos que a la hora de estudiar la infantería jenízara, debe prestarse especial importancia al cambio de lógica que supuso el siglo XVII. Así, nos encontramos, nominalmente, con un mismo cuerpo militar cuyo desarrollo condujo a una transformación que enterró a la original y virtuosa élite militar del Imperio Otomano. Así, se produjo la transformación de este cuerpo que, nacido como un instrumento político, llegaría a convertirse en actor fundamental en la política otomana.

\footnotetext{
${ }^{77}$ Véase Tezcan, Baki, The Second Ottoman Empire... op. cit., en donde se fecha en la última leva devsirme en 1703 (p. 195), año a partir del cual podemos considerar totalmente implantados estos "segundos jenízaros".
} 